\title{
A multi-period scheduling of dynamic cellular manufacturing systems in the presence of cost uncertainty
}

\begin{abstract}
Cell-load variation is considered as a major shortcoming in cellular manufacturing systems. It can cause long queues in front of machines and impose extra costs to the cellular layouts. In this paper the impact of inflation on cell-load variation in cellular manufacturing systems is examined. For this purpose, a new method is proposed for scheduling dynamic cellular manufacturing systems in the presence of bottleneck and parallel machines. The aim is finding the trade-off values between in-house manufacturing and using outsource services while system costs are not deterministic and may be varied from period to period by inflation. To solve the model, a hybrid genetic and simulated annealing algorithms is developed because of the high potential of outcomes to be trapped in the local optima. The results are then compared in LINGO ${ }^{\circledR} 12.0$ software. In continue a Taguchi method (an orthogonal optimization) is used to estimate parameters of the proposed method in order to solve experiments derived from literature. Our findings show that the condition of dynamic costs affects the routing of materials in process and may induce machine-load variation that yield to cell-load diversity. An increase in changing costs causes the loading level of each cell to vary, which in turn results in the development of "complex dummy sub-cells." To measure the level of cell-load variation a new mathematical index is developed. Then, a new method is proposed for minimizing cell-load variation in the mentioned condition by using control lines. The results indicate that the proposed method can significantly reduce the level of cellload variation in CMS.
\end{abstract}

Keyword: Facilities planning and design; Cell scheduling; Cell-load variation; Part routing; Inflation rate 